\title{
Border Detection System for Fisherman using GPS and Arduino
}

\author{
Kumar Harsh \\ Research Intern, Electrical Department \\ National Institute of Technology, Jamshedpur \\ Jamshedpur, Jharkhand, India
}

Rishu Anand

Student, Electrical Department

LNJPIT, Chapra

Chapra, Bihar, India

\author{
Sarvesh Ranjan \\ Research Intern, Electrical Department \\ National Institute of Technology, Jamshedpur \\ Jamshedpur, Jharkhand, India \\ Abhishek Kumar \\ Student, Electrical Department \\ Vellore Institute of Technology, Chennai \\ Chennai, Tamil Nadu, India
}

\begin{abstract}
There has been several cases where the ignorant and poor fishermen of Tamil Nadu have unknowingly and due to lack of technical equipment and knowledge have crossed the international border of sea and has been arrested by Sri Lankan naval forces on the accusation of terrorism. These innocent fishermen with no fault of theirs get caught and get severe punishment for the fault they don't know about. Countries with the International Marine time Boundary Line (IMBL) will always have security problems and continuous life threatens for those fishermen whose family's main economic support is fishing. Even in the peninsular country like India has their boundary limit in the ocean, the people of these coastal regions has the main work of fishing, due to carelessness or without knowing their boundary limit of their country they cross the borders. So in order o solve this problem, our group took this as a challenge and we have found an easy and feasible way to solve this problem in which the fishermen would be given certain signals and a buzzer would sound as soon as they approach the border and thus they can remain at safe distance from the border. This would greatly help the poor and innocent fishermen to remain within the Indian borders and continue their work.
\end{abstract}

\section{INTRODUCTION}

GPS commonly known as Global Positioning System also known as Navstar GPS that provides geolocation and the information to a GPS receiver in all weather conditions, anywhere on or near the Earth where there is an unobstructed line of sight to four or more GPS satellites. GPS systems are extremely versatile and can be found in almost any industry sector. They can be used to map forests, help farmers harvest their fields, and navigate airplanes on the ground or in the air. GPS systems are used in military applications and by emergency crews to locate people in need of assistance. Hence with a wide variety of its usage the GPS technology to solve the problems faced by the fishermen.

Therefore a GPS modeled safety device has been made through which fishermen can be prevented from crossing the border by keeping a constant eye on the movement of ships in the ocean. GPS and Wi-Fi module have been incorporated with the ships. GPS module help us to detect the latitude and longitude of the particular place and as soon as these ships reach a particular location i.e. near the border the GPS will locate it and a buzzer will be sounded and a red light will glow, that will alert the fishermen and they could easily return back from the border. The motivation for this project was basically the real problem of fishermen who went to earn their livelihood in the ocean and accidentally cross the borders and face legal problems from the other countries. This urged us to really find an effective solution to this problem of the fishermen so that they do not face any problem while fishing in the ocean or seas.

\section{METHODOLOGY}

The GPS device will continuously give the signal which determines the latitude and longitude and indicates the position of fishermen to them. Then it gives the output which gets read and displayed in LCD. The global Positioning system (GPS) is a space-based satellite navigation system that provides location and time information in all weather conditions, anywhere on or near the Earth where there is an unobstructed line of sight to four or more GPS satellites. GPS module communicates continuously with the satellite for getting the coordinates of a particular place. Then we need to send these coordinates from GPS to our Arduino by framing a proper Arduino code. The coordinates of all places are continuously monitored and as soon as border is reached the latitude is matched and a red light glows, a buzzer is sounded and a message is displayed on the LCD stating "Warning! Do Not Cross".

The proposed system uses a GPS receiver which receives signal from the satellite and gives the current position of the boat. The proposed system is used to detect the border of the country through the specified longitude and latitude of the position, not only between Sri Lanka and India but all over the world. The particular latitudes and longitudes i.e. border coordinates can be predefined and this can be stored in a microcontroller memory. The current value is compared with predefined values and if these values are same, immediately the particular operation will be done i.e. the microcontroller gives the instruction to the alarm to buzzer. It also uses a message transmitter to send message to the base station which monitors the boats in the sea. The system provides an indication to both the fishermen and to coast guard. 



\section{HARDWARE AND COMPONENTS DESCRIPTION}

\section{A) Arduino Uno}

The Arduino Uno is a microcontroller board which is developed by a company that goes by the name Arduino. It is an open source microcontroller board and is based on ATmega328P microcontroller. The Arduino Uno has a set of digital as well as analog input and output pins that can be used in various circuits and expansion boards. It consists of 14 digital pins and 6 analog pins. It is programmable with Arduino IDE (Integrated Development Environment) using a type B USB cable. It works fine with voltages between 7 volts and 20 volts, although it is mostly used with a $9-\mathrm{V}$ battery. The name Uno is because it was among the first USB-based Arduino boards.

\section{B) GNSS-The Global Navigation Satellite System}

Global Navigation Satellite System (GNSS) is a huge collection of Satellite that provide signals from space and transmits position and timing related data to GNSS receivers. The receiver afterwards uses this data to determine locations. It can provide positioning to worldwide users on a continuous basis in all weather, irrespective of day or night, anywhere on or near the Earth provided the place has an unobstructed view of four or more GNSS satellites. GNSS satellites broadcasts signals from space that GNSS receivers uses to provide latitude, longitude and altitude. GNSS is made up of three segments: Space, Control and User. The Space Segment consists of 24 to 32 satellites in medium Earth orbit and also contains boosters required to launch them into orbit. The Control system is composed of a Master Control Station, an Alternate Master Control Station, and a host of dedicated and shared Ground Antennas and Monitor Stations. The User segment is composed of hundreds of thousands of allied military users of the secure GNSS Precise Positioning Service and tens of millions of civil, commercial and scientific users of the Standard Positioning Service. GNSS is widely being used worldwide for navigation purposes, tracking and surveillance.

\section{C) Power Supply-}

DC motor and Microcontroller requires some power source. This power is supplied using a DC power supply ranging from $-+5 \mathrm{~V}$ to $-+12 \mathrm{~V}$. The available energy source is of $230 \mathrm{v}-50 \mathrm{~Hz}$, and a centre tapped step down transformer is used. The Arduino operates at low power.

D) Relay-

A Relay is an electrically operated switch. It consists of a set of input terminals for a single or multiple control signals, and a set of operating control terminals. Relays are used where it is needed to control a circuit by an independent low power signal. It is also used where it is needed to control several circuits by one signal. The conventional form of a relay uses an electromagnet to close or open the contacts. There are several other operating principles that have been invented, one of those are in solid state relays. It uses semiconductor properties for control and does not rely on moving parts.

\section{E) Buzzer-}

A Buzzer is an electronic device for signaling purposes. These are mostly used in automobiles, household appliances and other electronic devices. It has a number of switches connected to control unit that determines if and which button was pushed, or if a preset time has lapsed, and sounds a warning in the form of a continuous buzzing or beeping sound.

If the boat approaches the restricted area, the buzzer will sound automatically and will keep on beeping by means of pulse width modulation.

\section{F) LCD Display-}

The Liquid Crystal Display is a flat-panel display which uses liquid crystals in its primary form of operation. Light modulating property of liquid crystal is used in LCDs. Liquid Crystals does not emit light directly, instead it uses backlight or reflector to produce images or information in color or monochrome. The LCD used is a $2 \times 16$ LCD module. This is an alphanumeric LCD display and can display both alphabets and numbers. The Pin 1 is connected to the ground. The pin 2 powers the LCD with required supply. The pin 3 decides the contrast level of display. It is grounded for maximum contrast. The pin 4 is Register select that is connected to the microcontroller to shift between command and data register. The pin 5 is a Read or Write, it is used to read or write data. It is normally grounded for writing. The pin 6 is connected to the microcontroller pin and toggled between 0 and 1 for data acknowledgement. The pins numbered from 7 to 14 are data pins. These form an 8-bit data line and are connected to microcontroller to send 8-bit data. The pin 15 is Backlight LED pin positive terminal and the pin 16 is Backlight LED pin negative terminal.

\section{SYSTEM DESIGN AND RESULTS}

The system was successfully configured and tested with successful result with a given looped coordinates. 




The above picture indicates the scenario where the boat is going to cross the International borders and the system starts warning the sailor.



The above picture explains the scenario where the boat is sailing in safe zone and is can go ahead without any fear..

\section{CONCLUSION}

BORDER DETECTION SYSTEM FOR FISHERMEN using Arduino and GNSS is a model for Boat Navigation unit which can be implemented by using Google maps and GPS alongwith GNSS receivers and GSM modem. The information comes from the GNSS in the form of coordinates i.e. in the form of latitudes and longitudes. As many fishermen unknowingly crosses the maritime border between India and Sri Lanka, this
Navigation System will help them know their position and will allow them to avoid the consequences of crossing the border. The project is low budget and it will help the poor fishermen to a great extent. This navigation system provides sufficient information to both the coastal guards and to the fishermen

\begin{tabular}{|c|c|c|c|c|c|c|c|c|}
\hline 5 & 12.843 & 80.153 & 871 & $04 / 02 / 201808: 51: 151006$ & 13.60 & 5 & 1148955 & 0 \\
\hline 5 & 12.843 & 80.153 & 249 & $04 / 02 / 2018 \quad 08: 51: 17364$ & 18.30 & s & 1197658 & 0 \\
\hline 5 & 12.843 & 80.153 & 281 & $04 / 02 / 2018 \quad 08: 51: 18396$ & 18.80 & s & 1238360 & 0 \\
\hline 5 & 12.843 & 80.153 & 312 & $04 / 02 / 2018 \quad 08: 51: 19426$ & 19.20 & s & 1279062 & 0 \\
\hline 5 & 12.843 & 80.153 & 344 & $04 / 02 / 2018 \quad 08: 51: 20459$ & 21.10 & s & 1319764 & 0 \\
\hline 5 & 12.843 & 80.153 & 375 & $04 / 02 / 201808: 51: 21490$ & 21.80 & S & 1360466 & 0 \\
\hline 5 & 12.843 & 80.153 & 408 & $04 / 02 / 2018 \quad 08: 51: 22522$ & 22.50 & s & 1401168 & 0 \\
\hline 5 & 12.843 & 80.153 & 440 & $04 / 02 / 2018 \quad 08: 51: 23555$ & 23.50 & S & 1442070 & 0 \\
\hline 5 & 12.843 & 80.153 & 458 & $04 / 02 / 2018 \quad 08: 51: 24579$ & 25.20 & s & 1484172 & 0 \\
\hline 5 & 12.843 & 80.153 & 489 & $04 / 02 / 2018 \quad 08: 51: 25611$ & 26.60 & s & 1526274 & 0 \\
\hline 5 & 12.843 & 80.153 & 523 & $04 / 02 / 2018 \quad 08: 51: 26 \quad 644$ & 27.40 & s & 1568376 & 0 \\
\hline 5 & 12.843 & 80.153 & 566 & $04 / 02 / 2018 \quad 08: 51: 27681$ & 27.60 & S & 1609278 & 0 \\
\hline 5 & 12.843 & 80.153 & 597 & $04 / 02 / 2018 \quad 08: 51: 28713$ & 28.30 & s & 1650180 & 0 \\
\hline 5 & 12.843 & 80.153 & 630 & $04 / 02 / 2018 \quad 08: 51: 29746$ & 29.60 & s & 1691082 & 0 \\
\hline 5 & 12.843 & 80.153 & 661 & $04 / 02 / 201808: 51: 30776$ & 30.70 & s & 1731984 & 0 \\
\hline 5 & 12.843 & 80.153 & 693 & $04 / 02 / 201808: 51: 31808$ & 30.70 & S & 1772886 & 0 \\
\hline 5 & 12.843 & 80.153 & 725 & $04 / 02 / 2018 \quad 08: 51: 32839$ & 31.80 & s & 1813788 & 0 \\
\hline 5 & 12.843 & 80.153 & 757 & $04 / 02 / 2018 \quad 08: 51: 33873$ & 32.60 & s & 1854690 & 0 \\
\hline 5 & 12.843 & 80.153 & 789 & $04 / 02 / 2018 \quad 08: 51: 34905$ & 32.90 & s & 1895592 & 0 \\
\hline 5 & 12.843 & 80.153 & 849 & $04 / 02 / 2018 \quad 08: 51: 35989$ & 33.80 & s & 1948995 & 0 \\
\hline 5 & 12.843 & 80.153 & 250 & $04 / 02 / 2018 \quad 08: 51: 37373$ & 34.80 & s & 1998898 & 0 \\
\hline 5 & 12.843 & 80.153 & 279 & $04 / 02 / 201808: 51: 38401$ & 35.10 & s & 20407100 & 0 \\
\hline 5 & 12.843 & 80.153 & 322 & $04 / 02 / 2018 \quad 08: 51: 39437$ & 35.30 & s & 20814102 & 0 \\
\hline 5 & 12.843 & 80.153 & 356 & $04 / 02 / 2018 \quad 08: 51: 40471$ & 35.40 & s & 21221104 & 0 \\
\hline 5 & 12.843 & 80.153 & 389 & $04 / 02 / 201808: 51: 41504$ & 35.70 & S & 21628106 & 0 \\
\hline 5 & 12.843 & 80.153 & 418 & $04 / 02 / 201808: 51: 42533$ & 35.90 & s & 22035108 & 0 \\
\hline 5 & 12.843 & 80.153 & 440 & $04 / 02 / 2018 \quad 08: 51: 43562$ & 36.30 & SSE & 22454110 & 0 \\
\hline 5 & 12.843 & 80.153 & 486 & $04 / 02 / 201808: 51: 44602$ & 36.10 & SSE & 22861112 & 0 \\
\hline 5 & 12.843 & 80.153 & 513 & $04 / 02 / 201808: 51: 45628$ & 36.40 & SSE & 23268114 & 0 \\
\hline 5 & 12.843 & 80.153 & 548 & $04 / 02 / 2018 \quad 08: 51: 46664$ & 36.70 & SSE & 23675116 & 0 \\
\hline 5 & 12.843 & 80.153 & 579 & $04 / 02 / 201808: 51: 47694$ & 36.00 & SSE & 24082118 & 0 \\
\hline 5 & 12.843 & 80.153 & 610 & $04 / 02 / 2018 \quad 08: 51: 48726$ & 35.70 & SSE & 24489120 & 0 \\
\hline 5 & 12.843 & 80.153 & 642 & $04 / 02 / 2018 \quad 08: 51: 49757$ & 35.50 & SSE & 24896122 & 0 \\
\hline 5 & 12.843 & 80.153 & 671 & $04 / 02 / 201808: 51: 50786$ & 36.40 & SSE & 25303124 & 0 \\
\hline 5 & 12.843 & 80.153 & 704 & $04 / 02 / 201808: 51: 51820$ & 37.50 & SSE & 25710126 & 0 \\
\hline 5 & 12.843 & 80.153 & 739 & $04 / 02 / 2018 \quad 08: 51: 52856$ & 37.10 & SSE & 26117128 & 0 \\
\hline
\end{tabular}

The system is very cheap and can be widely used to save the poor fisherman from getting imprisonment due to lack of awareness.

\section{REFERENCES}

[1] J Suresh.M , Gandhiraj.S , Saranya.T , Thenmozhi.S , Divya.M, 2014. Border Alert System for Boats Using Zigbee. International Journal of Innovative Research in Computer and Communication Engineering

[2] S. Vivek T.V. Aravind Venkatraman L. Aravinth G. Raagul, 2015. Automatic Border Crossing Detection and Navigation of Boat. IJSTE International Journal of Science Technology \& Engineering | Volume 1 | Issue 8 | GPS-based vessel position monitoring and display system. IEEE Aerospace and Electronic Systems Magazine. 1990

[3] The accuracy of the global positioning systems. IEEE Instrumentation \& Measurement Magazine. 2004; 7(1): 56-60K. Elissa,

[4] GPS-based vessel position monitoring and display system. IEEE Aerospace and Electronic Systems Magazine. 1990

[5] Abid khan and Ravi Mishra (2012) , "GPS - GSM Based Tracking System” International Journal of Engineering Trends and Technology Volume3 Issue2 